Eurasian Studies in Business and Economics 5

Series Editors: Mehmet Huseyin Bilgin · Hakan Danis

Mehmet Huseyin Bilgin

Hakan Danis

Ender Demir

Ugur Can Editors

Country Experiences in

Economic Development,

Management and

Entrepreneurship

Proceedings of the 17th Eurasia

Business and Economics Society

Conference 


\title{
The Role of Internal Stakeholders in the Process of Creation Social Responsible Long-Term Care System in Poland
}

\author{
Joanna Ejdys
}

\begin{abstract}
One of the most important challenges of Europe, North America and Eastern Asia are the processes associated with the ageing (greying) population. The share of older people in Poland increased from $10.1 \%$ in 1990 to $14.4 \%$ in 2013 , while in Europe the share of older people increased from 13.9 to $18.2 \%$ between 1990 and 1992. Globally, the number of older people is expected to more than double, from 841 million people in 2013 to more than two billion in 2050. Processes associated with the ageing population will result in a steady increase of interest in long-term care services, such us residential care. On the other hand, the increasing demand for services of residential care will be caused by the fact that globally only $40 \%$ of older people live independently. The growing demand for residential care services will be accompanied by a growing interest in the quality and innovativeness improvement. From the perspective of the development corporate social responsibility of such units, the involvement of residents seems to be crucial. This paper presents the survey research results conducted among 169 residential care units in Poland. The scientific purpose of the article is principally to examine the existing relations between two variables: staff engagement (SE) and residents' engagement (RE) in residential care units in Poland. For this purpose, the multiple regression analysis was used.
\end{abstract}

Keywords Aging population $•$ CSR $•$ Staff engagement $\bullet$ Residents' engagement

\section{Introduction}

One of the most important observed global trends is the process of population growth and negative changes in age structure of the population with the same time. This process is, so important either from sociological and economical point of view. According to RAND (2013), the world population in the perspective of 2050 years will be ranged from 8 to 9.6 billion people. Forecast prepared by United Nations

\footnotetext{
J. Ejdys $(\bowtie)$

Faculty of Management, Bialystok University of Technology, Bialystok, Poland e-mail: j.ejdys@pb.edu.pl
} 
(2013), indicate that the population amounting in 2013 at the level of 7.2 billion people will systematically increase to 8.1 billion in 2025, to 9.6 billion in 2050 and 10.9 billion in 2100 years.

The overall positive phenomenon, related to the growth of the world population is nevertheless accompanied by negative changes related to the changing age structure of the population. The dynamics of the phenomenon associated with the growth of the population is highly dependent on (1) the fertility rate and (2) life expectancy (Guerin et al. 2015). According to the United Nations (2013), it is estimated that globally the fertility rate (births) will drop from 2.53 children per woman in the period 2005-2010 down to 2.24 children per woman in the period 2045-2050 and 1.99 in the period 2095-2100. The decreasing growth rate of the population, along with the large decline in the fertility rate is the main cause of population aging, manifested in the growing share of people above 65 years of age in the population structure in general. This process is becoming crucial for most of the world, both in terms of challenges and risks. This process is the result of progress in the development of technology, medicine and socio-economic changes.

According to the United Nations (2013), life expectancy will increase from 69 in the period 2005-2010 to 76 years in the period 2045-2050 and 82 in the perspective of the period 2095-2100. In the more developed countries the projected increase in life expectancy will be: from 77 years in the period 2005-2010, to 83 years in the period 2045-2050, to 89 in the period 2095-2100. However, in the less developed countries, the increase will be lower and will amount to: from 67 years of age in the period 2005-2010, to 75 years in the period $2045-2050$, to 81 in the period 2095-2100. Taking into account these determinants, it is estimated that in 2020 the number of people aged over 60 will reach one billion people and nearly two billion people by 2050 , comprising $22 \%$ of the population (Bloom et al. 2011). Globally (Department of Economic and Social Affairs 2013), it is estimated that the number of people of the analyzed age group will triple in the perspective of the year 2100 from 841 million in 2013 to three billion in the year 2100 .

The aging population phenomenon also occurs in Poland. According to the CSO (2014a) in the period of 1980-2013 the share of people aged over 65 years in the structure of the total population in Poland increased from 10.04 to $14.74 \%$. The total number of older people in the reporting period increased more than two million from the level of 3589 to 5672 people. The projected share of the population in the three main age groups in the year 2050 in Poland (Table 1) indicates that the number of people aged over 65 will increase from 5.672 to 11.097 million people, which means an increase of over $95 \%$. The share of people aged over 65 years in the structure of the population, will rise from $14.7 \%$ (in 2013) to $32.7 \%$ in 2050.

The population aged over 80 years of age plays a special role in the population age structure. The reduction of fitness after this age reduces the capability to function independently in the society. The analysis of statistical data points to strong growth in the number of people aged over 80, among people above 60 years of age. At the turn of 1980's and 2013 according to the CSO data (2014a), this share increased from 14.6 to $24.1 \%$. 
Table 1 Population forecast in age group in Poland (person)

\begin{tabular}{l|l|l|l|l}
\hline \multirow{2}{*}{ Year } & \multicolumn{2}{|l|}{ Projected number of people } & \multirow{2}{*}{ Total } \\
\cline { 2 - 5 } & $0-17$ years & $18-64$ years & More than 65 years & $38,495,659$ \\
\hline 2013 & $6,995,362$ & $25,827,689$ & $5,672,608$ & $33,950,569$ \\
\hline 2050 & $4,963,366$ & $17,889,715$ & $11,097,488$ & \\
\hline
\end{tabular}

Source: CSO (2014b)

The processes associated with the ageing population will result in a steady increase of interest in long-term care services, such us residential care. Residential care refers to the services of care and social support, other than nursing homes, provided in supported living arrangements (OECD 2008). On the other side, the increasing demand for services of residential care will be caused by the fact that globally only $40 \%$ of older people live independently, that is to say, alone or with their spouse only (Department of Economic and Social Affairs 2013). The growing demand for residential care services will be accompanied by a growing interest in quality and innovativeness improvement, and increasing requirements for longterm care services from the perspective of family who paid for such services. More often residents will be engaged into the process of improvement such services. From the perspective of development corporate social responsibility (CSR) of such units, engagement of residents seems to be crucial.

\section{Corporate Social Responsibilities Form Perspective of Stakeholders Theory}

Invaluable contribution to the development of corporate social responsibility has been made by the European Union. In the Green Paper published in 2001, the European Commission stressed that corporate social responsibility in business is the concept of an organization voluntarily taking into account the social and environmental aspects when conducting commercial activities and in relations with stakeholders (Commission of the European Communities 2001).

Being responsible means not only fulfilling legal requirements, but also investing in human capital, caring for the environment and building relationships with stakeholders (Ejdys et al. 2015; Czemiel-Grzybowska 2009). Depending on the nature of the conducted activity, organizations should adapt their own understanding of the concept of social responsibility for their own purposes.

The European Commission has gradually every few years published notices and reports indicating the directions of CSR development in the EU. In the latest Communication of 2011, the European Commission puts great emphasis on the responsibility of organizations for their impact on the society in the new definition of CSR. To fully fulfill these commitments, organizations should have at their disposal a mechanism for integrating the issues of social, environmental, and 
ethical nature, as well as those related to human rights, and the needs of consumers with its business strategy developed in close cooperation with the stakeholders.

An overview of definitions of the CSR concept indicated that the most prominent features of social responsibility include:

- an integrated approach to the three dimensions of sustainability: social, environmental and economic (it may be referred to as the " $3 \mathrm{P}$ " principle, from the English term "People-Planet-Profit");

- action for a better society;

- cooperation with stakeholders, i.e. everybody who is affected by business and who can influence business.

Taking into account the specific nature of the activities carried out by the nursing homes, the article focuses mainly on the third aspect of cooperation with stakeholders.

One of the constructs of the concept of corporate social responsibility is directing the organization's activities at the stakeholders. Stakeholder perspective is fundamental to face a CSR analysis (Matysiewicz 2013). As Matten et al. (2003) pointed out the stakeholder theory appears to be a necessary process in the operationalization of CSR.

Taking into account the relations with stakeholders, some definitions of the CSR concept indicate the need to meet the expectations of all the stakeholders (Singh et al. 2015; Aguilera et al. 2007; Clarkson 1995; Mazur 2015; Ejdys 2015), while others emphasize the need to involve stakeholders in the organizational processes through constant building of relationships with stakeholders (Waddock et al. 2002). According to Freeman and Reed's (1983) definition a stakeholder is "any identifiable group or individual who can affect the achievement of an organization's objectives, or is affected by the achievement of an organization's objectives." Research has underlined the merits of distinguishing different categories of stakeholders to allow managers to take right decision (Sobczak and Havard 2015). In practice, the division of the stakeholders into two groups can be distinguished: external stakeholders (consumers, contractors, suppliers, societies) and internal stakeholders (employees, owners, managers). The subject of scientific research is directed at the two distinguished groups of stakeholders. External stakeholders comprised the area of interest of Gonzalez-Rodriguez et al. (2015), analyzing the factors determining the perception of the concept of social responsibility by consumers, while the object of interest of Cordeiro and Tewari (2015) were the reactions of stock investors to the undertaking of CSR activities by large listed companies. Research carried out by Liu et al. (2015) showed how managers react and change their priorities in terms of CSR activities under the influence of external stakeholders. Sobczak and Havard (2015) analyzed impact of four external stakeholder groups on the CSR strategies of the five major French unions. Research on the relationship between activities in the field of CSR of organizations and external stakeholders, mainly concerned the impact on the stakeholders by assessing the effects of economic, social and environmental factors (results influence approach), on the other hand, it focused on the conscious adaptation of business operation to 
the principles of CSR under the influence of requirements and expectations of external stakeholders (put pressure approach).

Internal stakeholders were the objects of scientific interest in the context of the internal value to the organization and its employees that determine the practical application of the concept of CSR (Zhu and Zhang 2015), involvement of employees and managers in the process of socially responsible policy-making (Crisostomo et al. 2014), and their expectations (Monowar and Humphrey 2013).

The identification of stakeholders remains a debated issue among academics and business practitioners (Yang and Rivers 2009; Carroll and Shabana 2010). This process is also necessary to understand and manage their expectations and to enhance corporate image and competitive advantage (Monowar and Humphrey 2013). In a case with problems of stakeholder identification, it could be advantageous to use Carroll's recommendation for identifying stakeholders as societal members whose names and faces are urgent to business, and to whom it must be responsive (Carroll 1991). Indication of the key stakeholder group will be determined by kinds of business activity. A particular group of entities representing health and welfare services (in the form of hospitals, nursing homes) where "under one roof", at the same time, exist both the persons providing services, as well as their direct recipients (residents).

In a case of nursing homes, the internal stakeholders should be understood as both the workers and the residents who are the recipients of the services provided by nursing homes. Stakeholder that is not committed to the company or to the CSR concept is less likely to influence the company's CSR strategy (Sobczak and Havard 2015). Thus, the particular area of concern for the author was staff orientation and customer orientation in Polish nursing homes.

In this context, social responsibility of facilities such as nursing homes should be understood as a process of organizational learning and the involvement of both the employees and the residents, which consequently should lead to ensuring the satisfaction of both sides (Fig. 1).

The scientific purpose of the article was principally to examine the existing relations between two variables: staff engagement (SE) and residents' engagement (RE) in residential care units in Poland.

Through the process of residents' involvement, the author understands the set of activities allowing residents to actively participate in the creation of the service offer focused on ensuring their satisfaction. The process of involvement of employees manifests itself in particular in the participation in determining the strategic objectives of the organization, commitment to the organization's objectives and ensuring constant satisfaction of residents.

The following hypothesis was tested: High level of staff engagement (SE) will positively influence the process of residents' engagement (RE) in residential care units. 


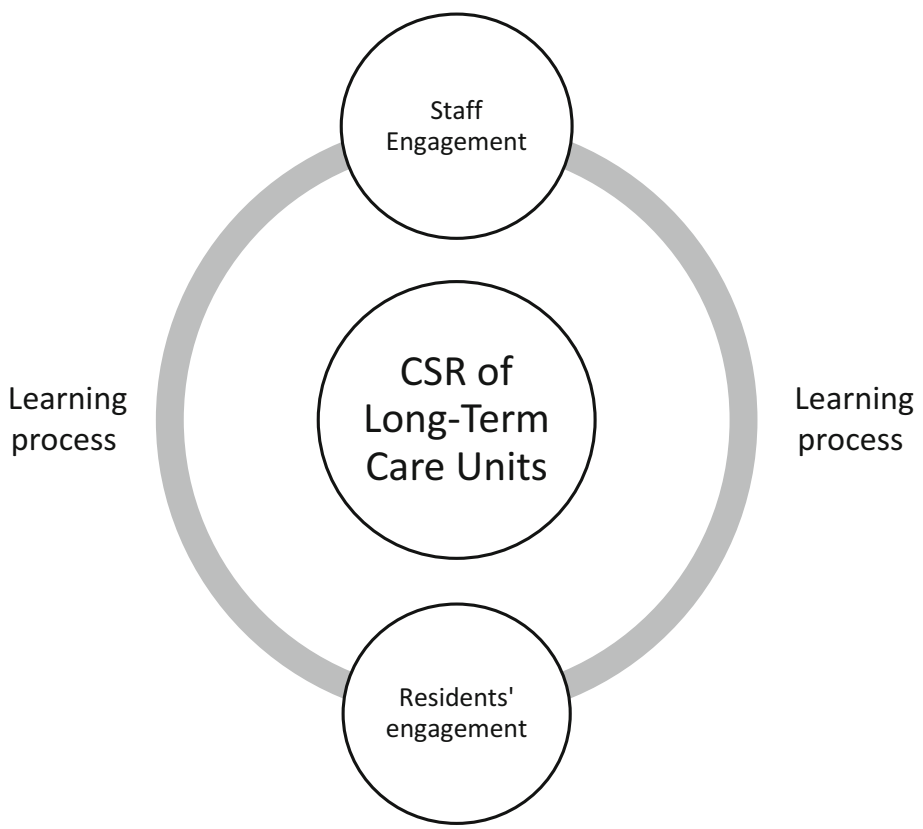

Fig. 1 Corporate social responsibilities of long-term care units

\section{Research Method}

\subsection{Data}

The data used to test the hypothesis was gathered from 169 residential care units in Poland. The questionnaire was sent to a total number of 804 residential care units in Poland. The rate of return was at the level of $21 \%$. The surveyed residential care units with a total number of 16,958 beds represent $21.1 \%$ of all available beds in residential care (nursing home) units in Poland $(78,793)$.

All residential care units offer living and nursing services to their residents. As presented in Table 2 among all 169 surveyed units $1.2 \%$ were micro companies (employment between 1 and 9 employees), 38.5\%-small sized companies (employment between 10 and 49 employees), and 58.0\%-medium firms (employment between 50 and 249 employees) and $2.4 \%$ were big enterprises (employees above 250 employees).

According to type of geographic market, surveyed residential care represented in $13.6 \%$ municipal units, in $54.4 \%$ district units and in $32.0 \%$ province units (Table 3). 
Table 2 Profile of the respondent units by employment size

Table 3 Profile of the respondent units by geographic market

\begin{tabular}{l|c|c}
\hline Employment size & Frequency & Percentage \\
\hline $1-9$ & 2 & 1.2 \\
\hline $10-49$ & 65 & 38.5 \\
\hline $50-249$ & 98 & 58.0 \\
\hline$>250$ & 4 & 2.4 \\
\hline Total & 169 & 100.0 \\
\hline
\end{tabular}

\begin{tabular}{l|c|c}
\hline Territorial extent & Frequency & Percentage \\
\hline Local (municipal) & 23 & 13.6 \\
\hline District (poviat) & 92 & 54.4 \\
\hline Province & 54 & 32.0 \\
\hline Total & 169 & 100.0 \\
\hline
\end{tabular}

\subsection{Measures}

In this study, the survey method was used to collect data. The questionnaire, conducted on the basis of confidentiality, was distributed between January 2015 and May 2015. All constructs were measured using a seven-point Likert scale to access the degree to which the respondent agreed or disagreed with each of the items $(1=$ totally disagree to $7=$ totally agree $)$. The constructs' Cronbach's alpha coefficients were used (Table 4). Author used the average score of measures of each construct for further analysis.

Due to the fact, that the examined constructs cannot be measured directly, the need to adopt direct measures appeared. The author adopted his own staff and residents' engagement scale. Five items measured staff engagement, four items measured residents' engagement (Table 5).

\section{Analysis and Results}

Among the analyzed characteristics (items) concerning the measurement of staff involvement, the ones that were rated most highly were the elements indicative of the fact that the organization interprets the information from the residents without a negative attitude (SE 5-5.96), and that the organization is not afraid of criticism from its residents (SE 4-5.93). The relatively low-rating was given to the fact of employees' engagement in the achievement of organizational objectives (SE 2-5.51) and the participation of employees in defining the organization's objectives (SE 3-5.51) (Fig. 2).

Analyzing the results regarding the involvement of the residents of social assistance institutions and taking into account the adopted measures, it can be observed that a relatively high rating was given to the evaluated elements indicative of the fact that the objectives of the organization are aimed at ensuring the 
Table 4 Cronbach's alpha, means and standard deviations

\begin{tabular}{l|l|l|l|l}
\hline & Alpha & Mean & Standard deviation & Obliquity \\
\hline Staff engagement (SE) & 0.821 & 5.73 & 0.862 & -1.247 \\
\hline Residents' engagement (RE) & 0.606 & 5.68 & 0.856 & -0.916 \\
\hline
\end{tabular}

Table 5 Constructs, measurement items

\begin{tabular}{|c|c|}
\hline \multicolumn{2}{|c|}{ Items descriptions } \\
\hline \multicolumn{2}{|c|}{ Staff engagement } \\
\hline SE1 & $\begin{array}{l}\text { The organization monitors and evaluates the level of commitment to ensure the satis- } \\
\text { faction of RCU residents }\end{array}$ \\
\hline SE2 & All employees demonstrate their commitment to the organization goals \\
\hline SE3 & All employees are partners in setting the organization's objectives \\
\hline SE4 & The organization is not afraid of criticism from their clients \\
\hline SE5 & $\begin{array}{l}\text { The organization analyses the information from their residents without any negative } \\
\text { attitude }\end{array}$ \\
\hline \multicolumn{2}{|c|}{ Residents' engagement } \\
\hline RE1 & The objectives of the organization are focused on ensuring the residents' satisfaction \\
\hline RE2 & Competitive advantage of the organization is based on understanding the residents' needs \\
\hline RE3 & The level of residents' satisfaction is constantly monitored \\
\hline RE4 & Residents are intensively involved in creating and improving the services \\
\hline
\end{tabular}

6.00

5.90

5.80

5.70

5.60

5.50

5.40

5.30

5.20

\subsection{2}

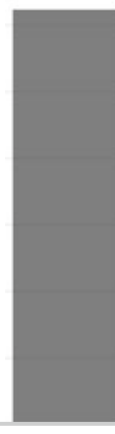

SE1

\subsection{1}

5.51

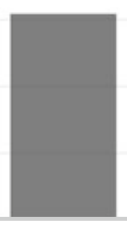

SE2
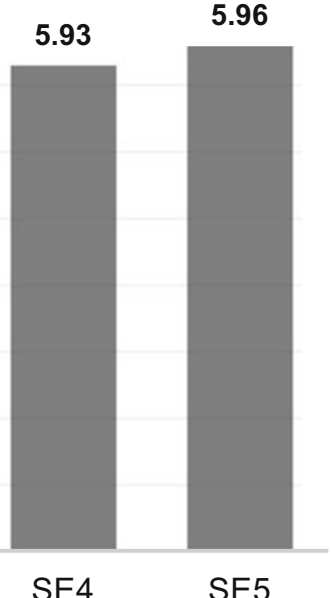

Fig. 2 Average rating of staff engagement characteristics

satisfaction of the inhabitants of the social assistance institution (RE1-2.28). The study of the unit has also indicated that the level of satisfaction of the residents of the social assistance institution is constantly monitored (RE3-5.83). In contrast, the involvement of the residents of social assistance institutions in the creation and 


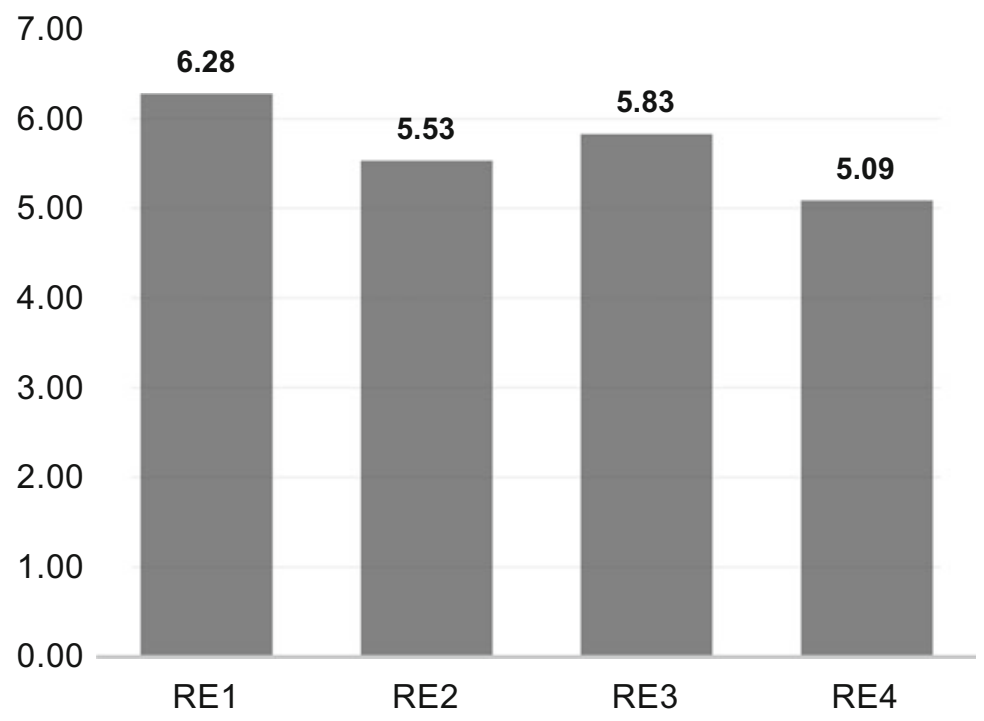

Fig. 3 Average rating of residents' engagement characteristics

Table 6 Correlation matrix

\begin{tabular}{l|l|l}
\hline & Residents' engagement (RE) & Staff engagement (SE) \\
\hline Residents' engagement (RE) & 0.00 & $0.514^{* *}$ \\
\hline Staff engagement (SE) & $0.514^{* *}$ & 0.00 \\
\hline
\end{tabular}

**Correlation is significant at the level of 0.01 (bilaterally)

improvement of the offer of the provided services received a relatively low rating (RE4-5.09). It can be seen that this is an area for potential improvement (Fig. 3).

To find the answer for the research question and verify the hypothesis, the author used a two-step approach. First, the correlation analysis was applied, and then the author followed up with the regression analysis. To investigate whether the engagement is strongly correlated with the staff engagement, the correlation analysis was undertaken. Table 6 shows correlation matrix for variables.

Table 6 shows a significant correlation between the residents' engagement and staff engagement. Table 7, reports the results of the follow-up regression analysis, in particular the beta coefficients for the parameters. According to the achieved results, hypothesis H1 was supported. Regression analysis showed that relation between residents engagement (RE) and staff engagement (SE) is statistically significant $(\mathrm{p}<0.05)$. 
Table 7 Results of multiple regression analysis

\begin{tabular}{|c|c|c|c|c|c|}
\hline \multirow[b]{2}{*}{ Specification } & \multicolumn{2}{|c|}{ Unstandardized coefficient } & \multirow{2}{*}{$\begin{array}{l}\text { Standardized } \\
\text { coefficient } \\
\text { Beta }\end{array}$} & \multirow[b]{2}{*}{ t-value } & \multirow[b]{2}{*}{ p-value } \\
\hline & B & Standard error & & & \\
\hline Fixed & 2.761 & 0.382 & & 7.235 & 0.000 \\
\hline Staff engagement (SE) & 0.510 & 0.066 & 0.514 & 7.742 & 0.000 \\
\hline $\mathrm{F}$ & 59.938 & & & & \\
\hline $\mathrm{p}$ & 0.000 & & & & \\
\hline
\end{tabular}

Dependent variable: RE—residents engagement

Predictor: SE—staff engagement

\section{Conclusions}

The study aimed to examine relationships between two construct of the social responsible concept used in residential care units: staff engagement and residents' engagement. Research studies carried out among Polish residential care units (169) confirmed the existing statistically significant positive relationship between staff engagement and residents' engagement.

From the perspective of the stakeholder theory, corporate social responsibility of units such as nursing homes depends on the involvement of the internal stakeholders, including the employees (staff) and the residents (pensioners).

The conducted research showed a rather low level of involvement of employees in the process of defining and then commitment towards the implementation of strategic objectives of the organization. The strategic planning process, and in particular the determination of the organization's objectives should be participatory in nature, involving all employees. Earlier involvement of employees in the process of formulating objectives ensures their actual involvement on later stages, arising from a sense of responsibility for setting those objectives.

Evaluation of the level of involvement of residents confirmed the relatively low share of this group of stakeholders in the creation and improvement of services provided to residents. In the context of the theory of quality management, and taking into account the specificities of the analyzed elderly care services, without knowing their expectations and their simultaneous participation in the creation of added value, it is not possible to provide complete satisfaction by this group of stakeholders.

In the context of future research, it seems advisable to determine which type of action should to the greatest extent be undertaken by both the staff and the residents themselves. Without a doubt such an area is the improvement of the quality of services, which should have a direct impact on the increase in the level of customer satisfaction (residents). The surveys concerning the satisfaction of the residents and the factors determining it are an important potential area for further research.

Acknowledgements The article was funded by the National Center for Science awarded on the basis of the decision number DEC-2011/01/D/HS4/05665. 


\section{References}

Aguilera, R. V., Rupp, D. E., Williams, C. A., \& Ganapathi, J. (2007). Putting the S back in corporate social responsibility: A multilevel theory of social change in organizations. Academy of Management Review, 32(3), 836-863.

Bloom, D.E., Canning, D., \& Fink, G. (2011). Implications of population aging for economic growth (NBER Working Paper No. 16705, Issued in January 2011). Retrieved November 26, 2015, from http://www.nber.org/papers/w16705.pdf

Carroll, A. B. (1991). The pyramid of corporate social responsibility: Toward the moral management of organizational stakeholders. Business Horizons, 34(4), 39-48.

Carroll, A. B., \& Shabana, K. (2010). The business case for corporate social responsibility: A review of concepts, research and practice. International Journal of Management Reviews, 12(1), $85-105$.

Clarkson, M. (1995). A stakeholder framework for analyzing and evaluating corporate social responsibility. The Academy of Management Review, 20(1), 92-118.

Commission of the European Communities. (2001). Green paper-Promoting a European framework for corporate social responsibility. Brussels: Commission of the European Communities.

Cordeiro, J. J., \& Tewari, M. (2015). Firm characteristics, industry context, and investor reactions to environmental CSR: A stakeholder theory approach. Journal of Business Ethics, 130(4), 833-849.

Crisostomo, L., de Souza Freire, V., Nobre Parente, F., \& Henrique, P. (2014). An analysis of corporate social responsibility in Brazil: Growth, firm size, sector and internal stakeholders involved in policy definition. Pensamiento \& Gestión, 37, 125-149.

CSO. (2014a). Demographic yearbook of Poland. Warsaw: Central Statistical Office.

CSO. (2014b). Population projection 2014-2050. Warsaw: Central Statistical Office.

Czemiel-Grzybowska, W. (2009). Corporate social responsibility (small and medium businesses). In M. Godlewska \& E. Weiss (Eds.), New trends and challenges in management: Company in process of integration with European Union (pp. 17-26). WSFiZ: Warszawa.

Department of Economic and Social Affairs. (2013). World population prospects: The 2012 revision (Paper No. ESA/P/WP.228). New York: UN.

Ejdys, J. (2015). Innovativeness of residential care services in Poland in the context of strategic orientation. Procedia-Social and Behavioral Sciences, 213, 746-752.

Ejdys, J., Ustinovicius, L., \& Stankevičiene, J. (2015). Innovative application of contemporary management methods in a knowledge-based economy: Interdisciplinarity in science. Journal of Business Economics and Management, 16(1), 261-274.

Freeman, R., \& Reed, D. (1983). Stockholders and stakeholders: A new perspective on corporate governance. Californian Management Review, 25(2), 88-106.

Gonzalez-Rodriguez, M. R., Diaz-Fernandez, M. C., \& Simonetti, B. (2015). The social, economic and environmental dimensions of corporate social responsibility: The role played by consumers and potential entrepreneurs. International Business Review, 25, 836-848.

Guerin, B., Hoorens, S., Khodyakov, D., \& Yaqub, O. (2015). A growing and ageing population Global societal trends to 2030: Thematic report 1. Santa Monica, CA: RAND Corporation. Retrieved October 22, 2015, from http://www.rand.org/pubs/research_reports/RR920z1.html

Liu, Y., Feng, T., \& Li, S. (2015). Stakeholder influences and organization responses: A case study of corporate social responsibility suspension. Management and Organization Review, 11(3), 469-491.

Matten, D., Crane, A., \& Chapple, W. (2003). Behind the mask: Revealing the true face of corporate citizenship. Journal of Business Ethics, 45(1/2), 109-120.

Matysiewicz, J. (2013). Customer exclusion in Europe: The causes and consequences for financial markets. In: IER (The Institute of Economics, Russia. Ural Branch of Russian Academy of Sciences), 11th EBES Conference Proceedings. Ekaterinburg, Russia, 12-14 September 2013. Istanbul: EBES. 
Mazur, B. (2015). Sustainable human resource management. The attempt of holistic approach. Ekonomia i Zarzadzania, 7(2), 7-12.

Monowar, M., \& Humphrey, J. (2013). Stakeholder expectation of corporate social responsibility practices: A study on local and multinational corporations in Kazakhstan. Corporate Social Responsibility and Environmental Management, 20, 168-181.

OECD. (2008). Conceptual framework and definition of long-term care expenditure. Revision of the System of Health Accounts. Paris: OECD.

RAND. (2013). Europe's societal challenges: An analysis of global societal trends to 2030 and their impact on the EU. European Union. Retrieved October 22, 2015, from http://europa.eu/ espas/pdf/espas-report-societal-trends.pdf

Singh, R., Bakshi, M., \& Mishra, P. (2015). Corporate social responsibility: Linking bottom of the pyramid to market development? Journal Of Business Ethics, 131(2), 361-373.

Sobczak, A., \& Havard, C. (2015). Stakeholders' influence on French Unions' CSR strategies. Journal of Business Ethics, 129(2), 311-324.

Waddock, S., Bodwell, C., \& Graves, S. (2002). Responsibility: The new business imperative. The Academy of Management Executive, 16(2), 132-147.

Yang, X., \& Rivers, C. (2009). Antecedents of CSR practices in MNCs' subsidiaries: A stakeholder and institutional perspective. Journal of Business Ethics, 86, 155-169.

Zhu, G., \& Zhang, G. (2015). Evaluating practices and drivers of corporate social responsibility: The Chinese context. Journal of Cleaner Production, 100, 315-325. 